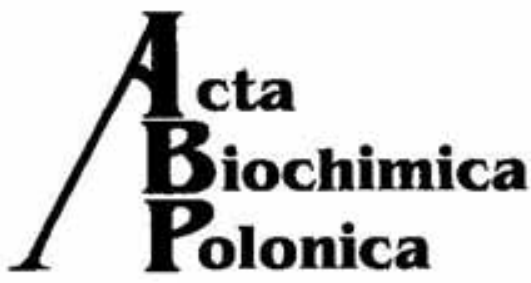

Vol. 43 No. 1/1996

Dedicated to Professor David Shugar on the occasion of his 80 th birthday

\section{Crystal structures of some acyclonucleosides with antiviral activity and related compounds}

\author{
Karin Bjåmer Birnbaum* \\ National Research Council of Canada, Ottawa, Canada, K1A OR6
}

Key words: acyclonucleoside, acyclonucleotide, antiviral agent, antiviral activity, cyclic monophosphate, cyclic phosphate, X-ray diffraction

The crystal structure of the acyclonucleoside, 9-[4-hydroxy-2-(hydroxymethyl)butyl]guanine (2HM-HBG), has been compared with related acyclonucleosides, and that of the acyclonucleotide, 9-[(1,3-dihydroxy-2-propoxy)methyl]guanine-3',5'-cyclic phosphate (DHPG-cMP), also with its parent second messenger cGMP and cyclic monophosphate nucleotides. There is considerable conformational flexibility in the acyclic chain of these compounds with several conformations coexisting in the solid state. This flexibility together with the narrow range of the glycosidic torsion angles (from $69^{\circ}$ to $94^{\circ}$, with an average of $83(3)^{\circ}$ for 11 molecules when the aglycon is guanine, and from $92^{\circ}$ to $108^{\circ}$ with an average of $103(3)^{\circ}$ for 4 molecules when the aglycon is adenine) may be essential for the antiviral activity of these compounds and their ability to act as substrates. The mechanism of antiviral activity of, 9-[(1,3-dihydro$x y$-2-propoxy)methyllguanine- $3^{\prime}, 5^{\prime}$-cyclic phosphate is different from that of the acyclonucleosides, and is discussed in the light of it being a close structural analogue to the second messenger cGMP.

The potent antiherpes activity of the clinically approved acyclovir stimulated the synthesis of a multitude of acyclonucleosides and nucleotides of purine and pyrimidine analogues. Many of these exhibit antiviral activity, and/or are inhibitors of specific enzymes which play key roles in chemotherapy [1]. The X-ray crystal structure determination of two of these compounds that was recently undertaken in collaboration with
Prof. Shugar and his coworkers at the University of Warsaw, will be reviewed below and compared with the structure of other related compounds: the first compound 2HM-HBG [2], is part of a group of acyclonucleosides that requires intracellular phosphorylation prior to exhibiting antiviral activity, while DHPG-cMP [3] is an acyclonucleotide that displays potent antiviral activity without prior "activation". DHPG-cMP may be active as such, i.e. as a

\footnotetext{
*NRCC No. 39095.

Abbreviations: ACV, acyclovir, 9-(2-hydroxyethoxymethyl)guanine; ganciclovir, DHPG, 2'-NDG, 9-[(1,3dihydroxy-2-propoxy)methyl]guanine; DHPG-cMP, DHPG 3':5'-cyclic phosphate, 9[Il(2-hydroxy-1,3,2dioxophosphorinan-5-yl)oxy]methyl]-P-oxide]guanine; DHPA, 9-(2',3'-dihydroxypropyl)adenine; DHPAde, 9-[(1,3-dihydroxy-2-propoxy)methyl]adenine; famciclovir, 9-[4-acetoxy-3-(acetoxymethyl)buty1]-2aminopurine); HBG, 9-(4-hydroxybutyl)guanine; 2HM-HBG, 9-[4-hydroxy-2-(hydroxymethyl)butyl]guanine; penciclovir, 9-[4-hydroxy-3-(hydroxymethyl)butyl]guanine; PMEA, 9-(2'-phosphonomethoxyethyl)adenine; TK, thymidine kinase; HCMV, human cytomegalovirus; cIMP, inosine cyclic $3^{\prime}, 5^{\prime}$ monophosphate; cUMPEt3.NH, triethylammonium salt of cyclic uridine-3', $5^{\prime}$-phosphate; cTMP phenylthymidine phenyl cyclic $3^{\prime}, 5^{\prime}$-monophosphate; cCMP, cytosine cyclic $3^{\prime}, 5^{\prime}$-monophosphate.
} 
structural analog of the second messenger cGMP.

\section{STRUCTURE OF 2HM-HBG}

\section{Background}

Several typical acyclonucleosides of guanine, including 2HM-HBG, the structure of which will be discussed below, are shown in Fig. 1. It should be noted that the acyclic chains may mimic the "upper" and/or "lower" portions of the sugar ring of natural nucleosides. The antiviral activities of these are dependant on their prior intracellular phosphorylation in infected cells by a virus-coded, but not cellular, nucleoside kinase, and subsequent phosphorylation to the triphosphates, which are usually selective inhibitors of the viral, relative to cellular, DNA polymerases. The racemate of $2 \mathrm{HM}-\mathrm{HBG}$ is a substrate for the thymidine kinases (TK) of herpes simplex viruses types 1 and 2, but not the cellular enzyme, and is an in vitro inhibitor of replication of these viruses [4]. Ganciclovir (DHPG) does not code for TK, but is a clinically promising agent $v s$ human cytomegalovirus (HCMV) and is phosphorylated by the HCMV UL97 gene product which shares regions of homology with protein kinases $[5,6]$. This lends added interest to the structure of $2 \mathrm{HM}$ -
HBG, which like DHPG contains two primary hydroxyls in the acyclic chain.

\section{Results}

2HM-HBG crystallizes with two independent molecules $A$ and $B$ together with one water molecule in the asymmetric unit, and the threedimensional structure and conformation is depicted in the stereoscopic view in Fig. 2.

In both the independent molecules, the side chain is approximately perpendicular to the plane of the aglycon, the torsion angles $\mathrm{C} 4-\mathrm{N} 9-$ $\mathrm{C1}^{\prime}-\mathrm{C}^{\prime}$ (equivalent to the glycosidic torsion angle $\chi$ in nucleosides) being $93.5^{\circ}$ and $86.0^{\circ}$, respectively, and hence in the range characterized as high syn and syn [7].

The acyclic chain in molecule $A$ is in the fully extended form with antiperiplanar orientation of the non-proton substituents on the chain about the bonds $\mathrm{C}^{\prime}-\mathrm{C}^{\prime}, \mathrm{C}^{\prime}-\mathrm{C}^{\prime}$, and $\mathrm{C}^{\prime}-\mathrm{C}^{\prime}$ as can be seen from the torsion angles in Table 1. The conformation of $\mathrm{Cl}^{\prime}$ and $\mathrm{O}^{\prime}$ ' about $\mathrm{C2}^{\prime}$ $-\mathrm{C}^{\prime}$ is gauche (+ synclinical). The largest deviation from $180^{\circ}$ is $23^{\circ}$ and occurs in the $\mathrm{C} 1^{\prime}-\mathrm{C} 2^{\prime}$ $\mathrm{C}^{\prime}-\mathrm{C}^{\prime}$ angle $\left(157.1^{\circ}\right)$. By comparison, the acyclic chain in molecule B is partially folded, a conformation that is stabilized by the formation of an intra-molecular hydrogen bond between $\mathrm{O}^{\prime} \mathrm{H}$ and $\mathrm{N} 3$ of the guanine ring. This is achieved by a rotation of the hydroxy-methyl<smiles>CC(CO)OC(F)(F)n1cnc2c(=O)[nH]c(N)nc21</smiles>

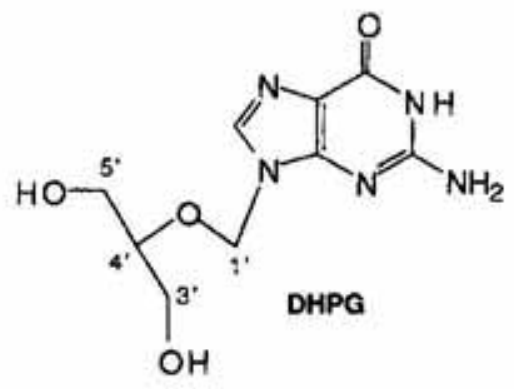<smiles>[R]C(CO)[C@@H]([18OH])n1cnc2c(=O)[nH]c(N)nc21</smiles>

Fig. 1. Structures of acyclonucleosides: $A C V ; D H P G ; H B G(R=H)$, Buciclovir $(R=O H)$, Penciclovir ( $R$ $\left.=\mathrm{CH}_{2} \mathrm{OH}\right) ; 2 \mathrm{HM}-\mathrm{HBG}$. Note that the carbons in the acyclic chains are numbered like the corresponding carbons of the pentose ring. 

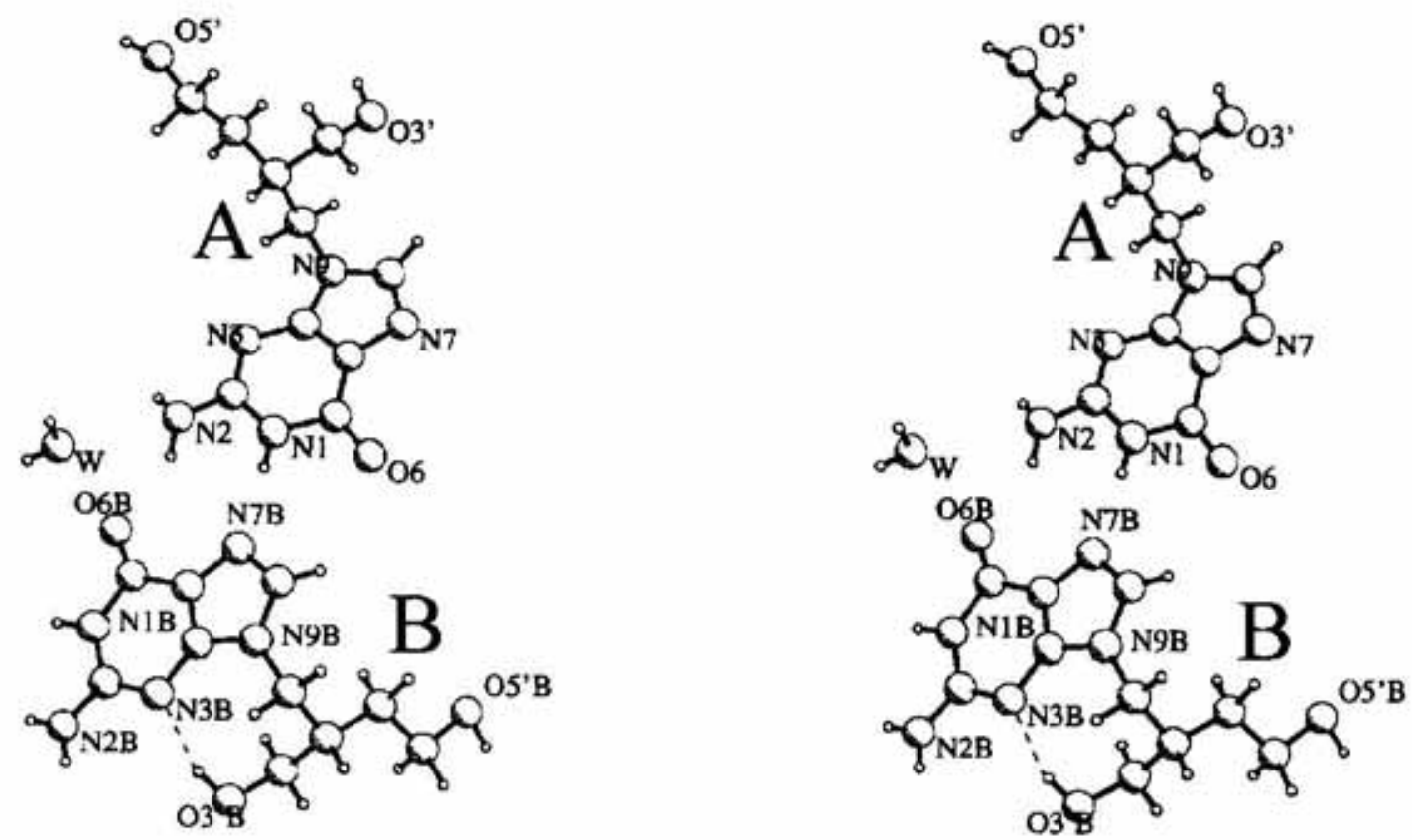

Fig. 2. Stereoscopic view of the solid state structure of $2 H M-H B G$, showing the two independent molecules $A$ and $B$, and one water molecule, in the asymmetric unit.

group about the $\mathrm{C}^{\prime}-\mathrm{C} 2$ ' bond, so that the atoms $\mathrm{N} 9$ and $\mathrm{C}^{\prime}$ ' are in the + gauche $(+\mathrm{sc})$ orientation, with a torsion angle of $65.9(3)^{\circ}$ for $\mathrm{N} 9-\mathrm{Cl}^{\prime}-\mathrm{C} 2^{\prime}$ $-\mathrm{C}^{\prime}$. There is also a rotation about the $\mathrm{C}^{\prime}-\mathrm{C}^{\prime}$ bond to a -synclinical conformation, manifested by the $\mathrm{C}^{\prime}-\mathrm{C}^{\prime}-\mathrm{C}^{\prime}-\mathrm{O}^{\prime}$ angle of $-179.5^{\circ}$, with the atoms $\mathrm{C}^{\prime}$ ' and $\mathrm{O}^{\prime}$ trans ( $(-a p)$ to each other. This intramolecular hydrogen bond is creating an eight-membered ring where $\mathrm{Cl}^{\prime}$, $\mathrm{C} 22^{\prime}, \mathrm{C}^{\prime}$, and $\mathrm{N} 3$ are very close to being in one plane, $\mathrm{C} 4$ and $\mathrm{N} 9$ are displaced to one side by equal amounts, $0.997(5) \AA$ and $1.001(5) \AA$, and $\mathrm{O}^{\prime}$ and $\mathrm{HO}^{\prime}$ ' by $-1.219(5) \AA$ and $-1.00(4) \AA$ to the other side.

\section{Comparison of $2 \mathrm{HM}-\mathrm{HBG}$ with related compounds}

The crystal structure of 2HM-HBG may be compared with that of other acyclonucleosides with the same base and with similar characteristics of the side chain, viz. HBG [8], penciclovir [9], DHPG (see [10]), and acyclovir [11], the latter two with an oxygen instead of the $\mathrm{C}^{\prime}$ methylene in the side chain. Comparisons of torsion angles are shown in Table1. The conformation of molecule A is closely related to other structures with fully extended chains, viz. HBG, penciclovir, DHPG, and molecule C of acyclovir, while that of molecule $B$ resembles more those with folded chains, viz. molecules $A$ and
$\mathrm{B}$ of acyclovir. In the light of the recent finding that DHPG is a clinically promising agent against human cytomegalovirus and may adopt a conformation resembling some local peptide region of a protein kinase substrate, it is particularly interesting to see the similarity of the fully extended molecule of $2 \mathrm{HM}-\mathrm{HBG}$ to that of DHPG, even though the $\chi$ values differ by $23.8^{\circ}$.

\section{Glycosidic torsion angle}

The orientation of the aglycon, approximately perpendicular to the side chain, compares well with the values of the other compounds in Table 1 . It should be noted that the $\chi$ value is somewhat less for the folded molecule $\left(86.0^{\circ}\right)$, i.e. part of the chain is closer to N3, than for the fully extended one $\left(93.5^{\circ}\right)$. A similar pattern exists for ACV, but with a larger spread between the values for the folded $\left(76.5^{\circ}\right.$ and $74.4^{\circ}$ ) and extended $\left(90.5^{\circ}\right)$ chains.

The values range from $69^{\circ}$ to $94^{\circ}$, with an average of $83(3)^{\circ}$ for 8 molecules (Table 1) when the aglycon is guanine. With the aglycon being adenine rather than guanine, larger values were observed, ranging from $92^{\circ}$ to $108^{\circ}$ with an average of $102.6^{\circ}$ (high syn) for 4 molecules (Table 2). (It should be noted that high syn is actually anti). In PMEA [12] the side-chain is almost coplanar with the aglycon $\left(\chi=177^{\circ}\right)$. 
Table 1

Torsion angles $\left({ }^{\circ}\right)^{*}$ of the $2 H M-H B G$ side chain compared with those of $H B G$, penciclovir, DHPG and acyclovir

\begin{tabular}{|c|c|c|c|c|c|c|c|c|}
\hline \multirow{2}{*}{ Side chain } & \multicolumn{2}{|c|}{ 2HM-HBG } & \multirow{2}{*}{$\mathrm{HBG}^{* * *}$} & \multirow{2}{*}{$\begin{array}{l}\text { Penci- } \\
\text { clovir }\end{array}$} & \multirow{2}{*}{ DHPG** } & \multicolumn{3}{|c|}{$\mathrm{ACV}^{* * * * * *}$} \\
\hline & A & B & & & & A & B & C \\
\hline $\mathrm{C} 4 \mathrm{~N}^{\prime} \mathrm{Cl}^{\prime} \mathrm{Cl}^{\prime}[\mathrm{x}]$ & $93.5(4)$ & $86.0(4)$ & 88.4 & 84.6 & 69.7 & 76.5 & 74.4 & 90.5 \\
\hline $\mathrm{C} 8 \mathrm{~N}^{\prime} \mathrm{Cl}^{\prime} \mathrm{Cl}^{\prime}$ & $-82.5(4)$ & $-95.4(4)$ & -86.8 & -97.9 & & -97.3 & -104.3 & -91.4 \\
\hline $\mathrm{N} 9 \mathrm{Cl}^{\prime} \mathrm{C}^{\prime} \mathrm{C}^{\prime}$ & $-168.7(5)$ & $65.9(3)$ & -179.5 & trans & -152.1 & 76.9 & 66.3 & 173.3 \\
\hline $\mathrm{C}^{\prime} \mathrm{C}^{\prime} \mathrm{C}^{\prime} \mathrm{C} 5^{\prime}$ & $157.1(5)$ & 171.3(5) & 179.8 & trans & 157.0 & -173.2 & 176.2 & 171.9 \\
\hline $\mathrm{C}^{\prime} \mathrm{C}^{\prime} \mathrm{C}^{\prime} \mathrm{O}^{\prime}$ & 175.3(6) & $178.4(6)$ & 178.3 & trans & trans & -60.6 & -73.5 & 174.4 \\
\hline $\mathrm{N} 9 \mathrm{Cl}^{\prime} \mathrm{C} 2^{\prime} \mathrm{C} 3^{\prime}$ & $66.2(3)$ & $-60.5(3)$ & & & & & & \\
\hline $\mathrm{C}^{\prime} \mathrm{C} 2^{\prime} \mathrm{C}^{\prime} \mathrm{C} 5^{\prime}$ & $-78.2(4)$ & $-62.1(3)$ & & & & & & \\
\hline $\mathrm{Cl}^{\prime} \mathrm{C}^{\prime} \mathrm{C} 3^{\prime} \mathrm{O}^{\prime}$ & $54.4(3)$ & $-53.7(3)$ & & & & & & \\
\hline $\mathrm{C}^{\prime} \mathrm{C}^{\prime} \mathrm{C}^{\prime} \mathrm{O} 3^{\prime}$ & $-70.5(3)$ & $-179.4(5)$ & & & & & & \\
\hline
\end{tabular}

* When comparing these, it should be kept in mind that a torsion angle of, e.g. $173^{\circ}$. is the equivalent of $-187^{\circ}$.

** In DHPG and acyclovir there is an oxygen (O4') instead of $\mathrm{C}^{\prime}$.

***For clarity, the values reported here for $\mathrm{ACV}$ and $\mathrm{HBG}$ are the ones corresponding to the same hand as for $2 \mathrm{HM}-\mathrm{HBG}$.

This was assumed to be an example of a structure that most likely is an intermediate in the syn-anti conversion, and it was hence excluded from the average given above.

\section{Acyclic chain}

The conformation of the side chain of molecule A is similar to those of HBG, DHPG and molecule $\mathrm{C}$ of $\mathrm{ACV}$, the largest deviations being about $23^{\circ}$, viz. in the $\chi$ angle relative to the one

Table 2

Comparison of the glycosidic torsion angles $\chi\left({ }^{\circ}\right)$ when adenine is the aglycon (all listed for the same hand).

\begin{tabular}{|l|c|}
\hline \multicolumn{1}{|c|}{ Acyclonucleoside } & $x\left[\mathrm{O}^{\prime} \mathrm{C1}^{\prime} \mathrm{N} 9 \mathrm{C} 4\right]$ \\
\hline DHP-Ade (molecule A) & $104.3^{\circ}$ \\
\hline DHP-Ade (molecule B) & 107.5 \\
\hline S-DHPA & 105.0 \\
\hline RS-DHPA & 92.4 \\
\hline PMEA & $177^{* * *}$ \\
\hline Average & 102.6 \\
\hline
\end{tabular}

"It should be noted that in order to adhere to the more recent convention used here, the torsion angle $\chi$ for PMEA is converted from the one given in the original paper $\left[\mathrm{O}^{\prime}-\mathrm{Cl}^{\prime}-\mathrm{N9}-\mathrm{C} 8\right]$ by subtracting $180^{\circ}$, and is thus accurate only to $\pm 3^{\circ}$.

**This value has been excluded from the average. in DHPG and in the C1'-C2'-C4'-C5' angle relative to the corresponding angle in HBG. There is much more variation between the individual torsion angles of the extended chain in molecule A of 2HM-HBG than in both HBG and molecule $\mathrm{C}$ of $\mathrm{ACV}$, presumably due to the hydroxy-methyl substituent of the side chain in the former, while the latter two have no substituents. The conformation of the side chain of molecule $B$ is similar to those of molecules A and $B$ in $A C V$, with the chain folded about the $\mathrm{C1}^{\prime}-\mathrm{C} 2$ ' (or $\mathrm{C1}^{\prime}-\mathrm{O}^{\prime}$ ) bond. However, in acyclovir the oxygen atoms $\mathrm{O}^{\prime}$ ' and $\mathrm{O}^{\prime}$ ' are in the favoured gauche $(-\mathrm{sc})$ position, while in $2 \mathrm{HM}$ $\mathrm{HBG}$ where there is a carbon instead of $\mathrm{O}^{\prime}$, the conformation about the $\mathrm{C}^{\prime}-\mathrm{C}^{\prime}$ ' is trans (tap).

\section{Concluding remarks for $2 \mathrm{HM}-\mathrm{HBG}$ and other acyclic antiviral nucleosides}

There is considerable conformational flexibility in the acyclic chain of these compounds in the solid state. The structure of $2 \mathrm{HM}-\mathrm{HBG}$ is an example of two conformations coexisting in the asymmetric unit: one with the acyclic chain fully extended and the other with it partially folded and hence closer to that of the natural nucleoside. There are also two conformers in DHP-Ade and famciclovir [9], and even three conformers coexist for ACV. 
However, in spite of the conformational flexibility of the acyclic chain, the glycosidic torsion angles for these antiviral agents are all in the syn or high syn conformation within a relatively narrow range, viz. from $69^{\circ}$ to $94^{\circ}$, with an average of $83(3)^{\circ}$ for 8 molecules (Table 1) when the aglycon is guanine, and from $92^{\circ}$ to $108^{\circ}$ with an average of $103(3)^{\circ}$ for 4 molecules (Table 2) when the aglycon is adenine.

\section{STRUCTURE OF DHPG-CMP}

\section{Background}

In contrast to the compounds discussed above (Fig. 1), the cyclic phosphate of ganciclovir (DHPG-cMP, see Fig. 3) displays potent broadspectrum antiviral activity [13] without prior "activation" by intracellular phosphorylation by viral thymidine kinase, and is active against viruses which do not code for thymidine kinase [14]. Its mechanism of action, which still needs to be clarified, is thus independent of viral or cellular TK and it may be active as such, i.e. as a structural analogue of the second messenger cGMP. In fact, there are a number of reports to the effect that replication of viruses, including herpes simplex viruses and HIV, are modulated by intracellular levels of cAMP and cGMP [1, 15].

DHPG-cMP, which is readily taken up by cells, was the first nucleotide analogue described, and the first cyclic phosphate of an acyclonucleoside, with potent antiviral activity. In particular, it proved to be up to 20 -fold more effective than its parental drug DHPG against a cytomegalovirus infection in guinea pigs [16].
A number of cyclic phosphates of acyclonucleosides have been examined for their substrate/inhibitor properties, i.e. their ability to recognize various specific phosphodiesterases and nucleases, in order to try to elucidate the mechanism of antiviral activity of DHPG-cMP [15]. This study indicates that the recognition by a nucleolytic enzyme of the acyclic chain is determined by the presence of the $\mathrm{O}^{\prime}$ ' ether oxygen in DHPG-cMP, since this atom cannot be substituted with a carbon without loss of activity.

\section{Results}

The three-dimensional structure and conformation of DHPG-cMP in its zwitterionic form with N7 of the guanine base protonated, can be seen from the stereoscopic view (Fig. 4). Its principal conformational features are as follows: the aglycon is in the high syn conformation about the glycosidic bond with the glycosidic torsion angle [O $\left.4^{\prime}-\mathrm{Cl}^{\prime}-\mathrm{N} 9-\mathrm{C} 4\right] \chi$ of $93.1^{\circ}$; the acyclic chain is partially folded; the six-membered cyclic phosphate ring is in the chair form with $\mathrm{P}$ and $\mathrm{C}^{\prime}$ displaced in diametrically opposite directions from the plane through the other four atoms $\left(\mathrm{C}^{\prime}, \mathrm{O}^{\prime}, \mathrm{C}^{\prime}\right.$ and O5') by $0.717(3) \AA$ and $-0.628(5) \AA$, respectively; and $\mathrm{O}^{\prime}$ ' is attached to $\mathrm{C}^{\prime}$ in the axial position with respect to this ring. This structure is also consistent with NMR results that DHPGcMP exhibits a single conformer in solution with $\mathrm{O4}^{\prime}$ in the axial position [15].

\section{Comparison of DHPG-cMP with related compounds}

The structure of DHPG-cMP is comparable with those of cGMP sodium tetrahydrate [17]<smiles>Nc1nc2c(ncn2CO[C@H]2C[CH-]COP(=O)([O-])O2)c(=O)[nH]1</smiles><smiles>Nc1nc2c(ncn2[Te+]2[C+]C(O)[C@H]3OP(=O)([O-])OC[C@@H]3O2)c(=O)[nH]1</smiles>

Fig. 3. Structures of DHPG-cMP and cGMP. 
and the free acid of cGMP [18], both cyclic phosphates and structural analogues with identical conformations apart from small variations in bond angles and torsion angles. The conformation of the side chain is also compared to that of several acyclonucleosides, viz. the respective parent compound DHPG, DHP-Ade and acyclovir; all the appropriate torsion angles can be seen in Tables $3 a$, and $3 b$. In DHPG-cMP only the "upper" part of the ribose is present, which means that there is less rigidity in this structure than in that of cGMP and hence there is freedom of rotation not only around the $\mathrm{N} 9-\mathrm{Cl}^{\prime}$ bond, but also around the $\mathrm{C} 1^{\prime}-\mathrm{O}^{\prime}$ ' and $\mathrm{O} 4^{\prime}-\mathrm{C} 4^{\prime}$ bonds as in other acyclonucleosides. The preferred orientations around these bonds are described by their corresponding torsion angles.

\section{Glycosidic forsion angle}

The orientation of the aglycon relative to the sugar moiety (the glycosidic torsion angle [O4'C $\left.\left.1^{\prime}-\mathrm{N} 9-\mathrm{C} 4\right] \chi=93.1^{\circ}\right)$ is practically identical to that in the fully extended chains in 2HM-HBG $\left(93.5^{\circ}\right)$ and in acyclovir $\left(90.5^{\circ}\right)$, i.e. high syn (+ac) [7]. It lies in the range $69^{\circ}-94^{\circ}$ for the guanine acyclonucleosides listed in Table 1, whose average is $83(3)^{\circ}$ (syn). The glycosidic torsion angles of the parent cGMP sodium tetrahydrate $\left(78^{\circ}\right)$ and cGMP free acid $\left(82^{\circ}\right)$ are very close to this average and hence in the typical syn ( $\pm \mathrm{sc}$ ) conformation.

\section{Sugar moiety}

The geometrical arrangement of the acyclic side-chain, i.e. the part comprised of the atoms
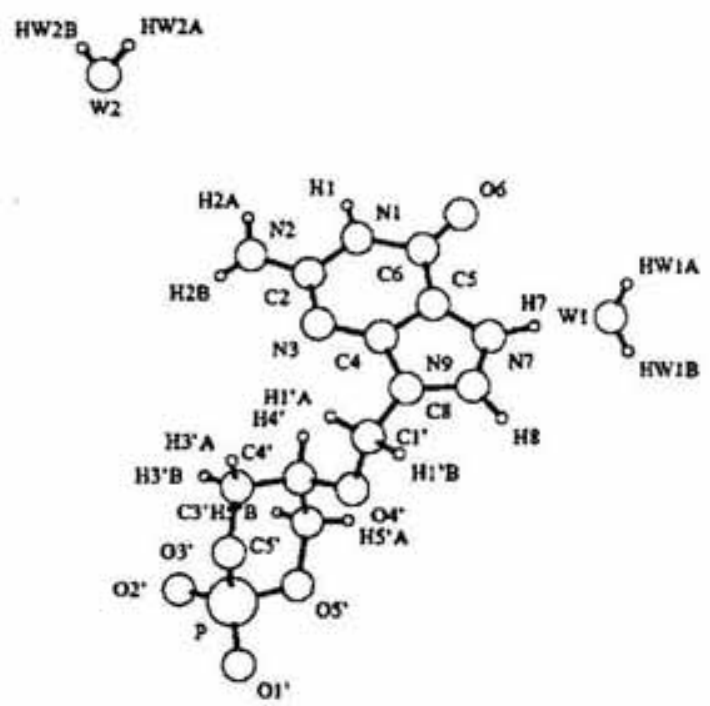

$\mathrm{C}^{\prime}, \mathrm{O}^{\prime}, \mathrm{C}^{\prime}$, and $\mathrm{C}^{\prime}$, is close to that of a sugar ring in the $\mathrm{C}^{\prime}$-endo envelope $\left({ }^{4} \mathrm{E}\right)$ conformation, but with the $\mathrm{C} 2^{\prime}$ atom missing. The two hydrogen atoms, $\mathrm{H}^{\prime} \mathrm{A}$ and $\mathrm{H}^{\prime} \mathrm{A}$, attached to $\mathrm{C}^{\prime}$ ' and $\mathrm{C}^{\prime}$ ', are fairly close $0.10(3) \AA$ and $0.30(4) \AA$, respectively) to the plane through the three atoms $\mathrm{C1}^{\prime}, \mathrm{C}^{\prime}$, and $\mathrm{O}^{\prime}$ while $\mathrm{C}^{\prime}$ is displaced by $0.780 \AA$ to the opposite side. The C4'-endo envelope corresponds to a pseudorotation phase angle $\mathrm{P}$ of $237.7^{\circ}$ based on $v_{0}$ of $42.9^{\circ}$ and $v_{\max }$ of $-80.3^{\circ}$. With the sugar moiety being acyclic, there is much more puckering $\left(v_{\max }\right.$ value as large as $\left.-80.3^{\circ}\right)$ than in a fused system such as cGMP (Table $3 a$ ) where the conformation is twist ${ }_{4} \mathrm{~T}^{3}\left[\mathrm{C} 4^{\prime}\right.$ exo, $\mathrm{C}^{\prime}$ endo $]$ with $\mathrm{P}$ and $v_{\max }$ values of $42.6^{\circ}$ and $44.2^{\circ}$, respectively. This is the usual conformation of nucleoside $3^{\prime}: 5^{\prime}$-cyclicphosphates as discussed below (cf. Table 4).

The first part of the side chain is folded, the $\mathrm{N} 9$ and $\mathrm{C}^{\prime}$ ' atoms being in the -gauche ( $-\mathrm{Sc}$ ) orientation, with a torsion angle of $-79.5(2)^{\circ}$ for N9-C1'-O4'-C4'. This is fairly close to the values in DHP-Ade $\left(-68.0^{\circ}\right.$ and $\left.-70.0^{\circ}\right)$, it is also gauche in molecules $\mathrm{A}$ and $\mathrm{B}$ of $\mathrm{ACV}\left(76.9^{\circ}\right.$ and $\left.66.3^{\circ}\right)$ but with opposite signs, and different from that in DHPG $\left(-152.1^{\circ}\right)$ and in molecule C of ACV $\left(-173.3^{\circ}\right)$ where it is trans and hence extended.

Another part of the side chain, viz. the atoms $\mathrm{C}^{\prime}, \mathrm{O}^{\prime}, \mathrm{C}^{\prime}$ ' and $\mathrm{C}^{\prime}$, form an almost extended chain, the $\mathrm{C}^{\prime} \mathrm{O}^{\prime} \mathrm{C}^{\prime} \mathrm{C}^{\prime}$ torsion angle being $157.0(3)^{\circ}$. The deviation of $23.0^{\circ}$ from an ideal extended chain is the same as that observed in DHPG, while the larger deviation of $44^{\circ}$ observed in DHP-Ade shows that the latter is
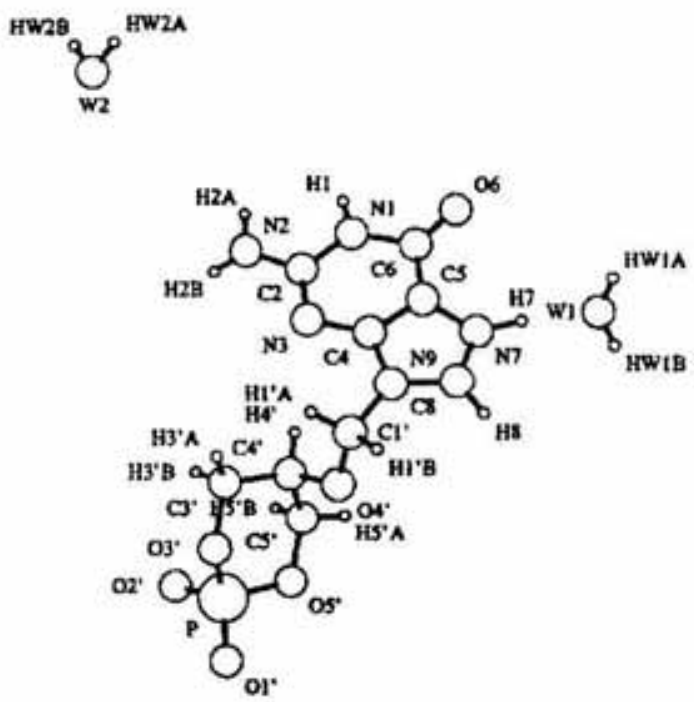

Fig. 4. Stereoscopic view of the solid state structure of DHPG-cMP and two molecules of water. 
Table 3a

Comparison of torsion angles $\left({ }^{\circ}\right)$ of DHPG-cMP sugar moiety and phosphate ring with those of cyclic GMP

\begin{tabular}{|c|c|c|c|}
\hline $\begin{array}{c}\begin{array}{c}\text { Glycosyl angle and sugar } \\
\text { moiety }\end{array} \\
\end{array}$ & DHPG-cMP & cGMPNa & cGMP, free acid \\
\hline$\chi\left[\mathrm{O}^{\prime} \mathrm{Cl}^{\prime} \mathrm{N} 9 \mathrm{C}^{\prime}\right]^{*}$ & $93.1(3)$ & 78 & 82 \\
\hline$v_{0}$ [here $\left.\mathrm{C}^{\prime} \mathrm{O}^{\prime} \mathrm{Cl}^{\prime} \mathrm{H1}^{\prime} \mathrm{A}\right]^{* *}$ & $42.9(17)$ & -18.4 & \\
\hline in $\left[\mathrm{O}^{\prime} \mathrm{Cl}^{\prime} \mathrm{C}^{\prime} \mathrm{C}^{\prime}\right]$ & & -9.3 & \\
\hline$v_{2}\left[\mathrm{Cl}^{\prime} \mathrm{C} 2^{\prime} \mathrm{C} 3^{\prime} \mathrm{C} 4^{\prime}\right]$ & & 31.7 & \\
\hline$v_{3}\left[\text { here } \mathrm{H}^{\prime} \mathrm{A} \mathrm{C}^{\prime} \mathrm{C}^{\prime} 4^{\prime} 4^{\prime}\right]^{* *}$ & $54.8(22)$ & -44.3 & \\
\hline$v_{4}\left[\mathrm{C}^{\prime} \mathrm{C}^{\prime} \mathrm{O}^{\prime} \mathrm{Cl}^{\prime}\right]$ & $-80.3(3)$ & 38.7 & \\
\hline$P$ & 237.7 & 42.6 & 44 \\
\hline Puckering & $\sim \sim^{4} \mathrm{E}$ & ${ }_{4} \mathrm{~T}^{3}$ & ${ }_{4} \mathrm{~T}^{3}$ \\
\hline \multicolumn{4}{|l|}{ Phosphate ring conformation } \\
\hline $\mathrm{C} 3^{\prime} \mathrm{O}^{\prime} \mathrm{PO}^{\prime}$ & $54.2(2)$ & 44.2 & \\
\hline $\mathrm{C}^{\prime} \mathrm{C}^{\prime} \mathrm{O}^{\prime} \mathrm{P}$ & $-59.1(2)$ & -59.8 & \\
\hline $\mathrm{C}^{\prime} \mathrm{C}^{\prime} \mathrm{C}^{\prime} \mathrm{O}^{\prime}$ & $55.5(2)$ & 68.5 & \\
\hline $\mathrm{C}^{\prime} \mathrm{C}^{\prime} \mathrm{C}^{\prime} \mathrm{O}^{\prime}$ & $-53.3(2)$ & -60.5 & \\
\hline $\mathrm{P} \mathrm{O}^{\prime} \mathrm{C5}^{\prime} \mathrm{C4}$ & $54.8(2)$ & 53.6 & \\
\hline $\mathrm{O}^{\prime} \mathrm{P} \quad \mathrm{O}^{\prime} \mathrm{C}^{\prime}$ & $-52.2(2)$ & -44.3 & \\
\hline
\end{tabular}

*It should be noted that in order to adhere to the more recent convention used here, the torsion angles $\chi$ for cGMP is converted from the ones given in the original papers $\left[04^{\prime}-\mathrm{C} !^{\prime}-\mathrm{N} 9-\mathrm{C} 8\right]$ by subtracting $180^{\circ}$, and are thus accurate only to $\pm 3^{\circ}$.

$*$ In caiculating $v_{0}$ and $v_{3}$ for DHPG-cMP the position of the hydrogen atoms H1'A and H3'A were used instead of the missing $\mathrm{C} 2$ '.

Table 3b

Comparison of torsion angles $\left({ }^{\circ}\right)^{*}$ of the DHPG-cMP side chain of acyclonucleosides that mimic the "upper" portion of the sugar ring of natural nucleosides

\begin{tabular}{|c|c|c|c|c|c|c|c|}
\hline \multirow{2}{*}{ Side chain } & \multirow{2}{*}{$\begin{array}{c}\text { DHPG } \\
\text {-cMP }\end{array}$} & \multirow{2}{*}{ DHPG } & \multicolumn{2}{|c|}{ DHP-Ade } & \multicolumn{3}{|c|}{$\mathrm{ACV}^{* *}$} \\
\hline & & & A & $\mathrm{B}^{* *}$ & A & B & $\mathrm{C}$ \\
\hline $\mathrm{O}^{\prime} \mathrm{Cl}^{\prime} \mathrm{N} 9 \mathrm{C} 4[x]$ & $93.1(3)$ & 69.7 & 104.3 & 107.5 & 76.5 & 74.4 & 90.5 \\
\hline $\mathrm{O}^{\prime} \mathrm{Cl}^{\prime} \mathrm{N} 9 \mathrm{C} 8$ & $-89.7(3)$ & & & & -97.3 & -104.3 & -91.4 \\
\hline $\mathrm{N} 9 \mathrm{Cl}^{\prime} \mathrm{O}^{\prime} \mathrm{C}^{\prime}$ & $-79.5(2)$ & -152.1 & -68.0 & -70.0 & 76.9 & 66.3 & 173.3 \\
\hline $\mathrm{C}^{\prime} \mathrm{O}^{\prime} \mathrm{C}^{\prime} \mathrm{C}^{\prime}$ & $157.0(3)$ & 157.0 & -135.5 & -137.8 & -173.2 & 176.2 & 171.9 \\
\hline $\mathrm{O}^{\prime} \mathrm{C}^{\prime} \mathrm{C}^{\prime} \mathrm{O}^{\prime}$ & $-64.3(2)$ & gauche & 61.4 & 52.6 & & & \\
\hline $\mathrm{O}^{\prime} \mathrm{C}^{\prime} \mathrm{C}^{\prime} \mathrm{O}^{\prime}$ & $67.8(2)$ & trans & 61.5 & 61.9 & -60.6 & -73.5 & 174.4 \\
\hline $\mathrm{C}^{\prime} \mathrm{C}^{\prime} \mathrm{C}^{\prime} \mathrm{O}^{\prime}$ & $55.5(2)$ & & -61.1 & -62.3 & & & \\
\hline $\mathrm{C}^{\prime} \mathrm{C}^{\prime} \mathrm{C}^{\prime} \mathrm{O}^{\prime}$ & $-53.3(2)$ & & -174.2 & 178.8 & & & \\
\hline
\end{tabular}

- When comparing these, it should be kept in mind that a torsion angle of, e.g. $-173^{\circ}$, is the equivalent of $187^{\circ}$.

**For clarity, the values reported here for ACV and molecule B of DHP-Ade are the ones corresponding to the same hand as for DHPG-cMP. 
more folded. In ACV, on the other hand, this part of the chain is fully extended with deviations being as small as $4^{\circ}-8^{\circ}$.

\section{Cyclophosphate ring}

The torsion angles of the phosphate ring are compared with those in cGMP (Table 3a). The conformation of the six-membered ring is the same in both compounds, but there is much more stress in CGMP due to the fusion with the ribose ring. This is manifested by an increased puckering in the $\mathrm{C}^{\prime}, \mathrm{C}^{\prime}$ ' half and a flattening in the $\mathrm{P}, \mathrm{O}^{\prime}, \mathrm{O}^{\prime}$ half of the phosphate ring. There are hence much greater variations in the torsion angles in cGMP than in DHPG-cMP.

One significant difference between the structure of DHPG-CMP and CGMP is that $\mathrm{O}^{\prime}$ is attached to the cyclic phosphate ring in the axial position in the former, while in cGMP it is equatorial which is dictated by the ribose ring being fused to the cyclic phosphate in the latter (Fig. 5).

The vicinal oxygen atoms all exhibit the favoured \pm gauche $\left( \pm 60^{\circ}\right)$ orientations about the $\mathrm{C}-\mathrm{C}$ bonds, the $\mathrm{O}^{\prime}-\mathrm{C}^{\prime}-\mathrm{C}^{\prime}-\mathrm{O}^{\prime}$ and $\mathrm{O}^{\prime}-\mathrm{C}^{\prime}$ $\mathrm{C} 5$ '-O5' being $-64.3(2)^{\circ}$ and $67.8(2)^{\circ}$, respectively. In DHP-Ade they are also both gauche, but both angles have the same sign and range in value from $52.6^{\circ}$ to $61.9^{\circ}$. In cGMP, on the other hand, they are in the less favoured trans position to each other since $\mathrm{O}^{\prime}$ ' is in the equatorial position, and $\mathrm{O}^{\prime}$ ' and $\mathrm{O}^{\prime}$ ' are also trans to each other in DHPG.

\section{Comparison of $3^{\prime}, 5^{\prime}$-cyclic monophosphate nucleotides}

In view of the reports that the biological specificity of cGMP is different from that of cAMP, and appears to have an opposing effect in cell proliferation and in other cellular events [19], and that the replication of viruses are modu-

Table 4

Comparison of glycosidic torsion angle $\mathrm{x}\left({ }^{\circ}\right)$, sugar, and phosphate ring conformations of DHPG-cMP with those of $3,5^{\prime}$-cyclic monophosphate nucleotides

\begin{tabular}{|c|c|c|c|c|c|c|}
\hline \multirow[b]{2}{*}{ Compound } & \multirow[b]{2}{*}{$\chi\left({ }^{\circ}\right)^{*}$} & \multicolumn{2}{|c|}{ Sugar } & \multirow[b]{2}{*}{$\begin{array}{l}\text { Phosphate } \\
\text { ring }\end{array}$} & \multirow[b]{2}{*}{$\mathrm{O}^{\prime}$} & \multirow[b]{2}{*}{ Reference } \\
\hline & & $\begin{array}{l}\text { Confor- } \\
\text { mation }\end{array}$ & $\mathrm{P}\left({ }^{\circ}\right)$ & & & \\
\hline DHPG-cMP & 93.1 (high sym) & $\sim{ }^{4} \mathrm{E}$ & 237.7 & chair & axial & [2] \\
\hline cGMPNa & $78($ sym $)$ & $4 T^{3}$ & 42.6 & chair & equatorial & [17] \\
\hline cGMP, free acid & 82 (syn) & $4 T^{3}$ & 44 & chair & equatorial & [18] \\
\hline CAMP $\quad$ (A) & $-118(a n t i)$ & $4 T^{3}$ & 38 & chair & equatorial & [30], see [25] \\
\hline (B) & $90($ syn $)$ & ${ }_{4} \mathrm{~T}^{3}$ & 50 & chair & equatorial & \\
\hline 5'-methylene-cAMP & 54 (syn) & ${ }^{3} \mathrm{~T}_{4}$ & 37 & chair & equatorial & [31] \\
\hline 8-[(2-aminoethyl)aminol-cAMP & $73($ syn $)$ & ${ }_{4} \mathrm{~T}^{3}$ & 51 & chair & equatorial & [32] \\
\hline 8-Bromo-cAMP & $109(a n t i)^{* *}$ & ${ }^{3} \mathrm{E}$ & 19 & chair & equatorial & see [25] \\
\hline cAMP, trigonal & -148 (anti) & ${ }^{3} T_{4}$ & 27 & chair & equatorial & [25] \\
\hline cAMPNa, monoclinic (A) & -149 (anti) & ${ }^{3} \mathrm{~T}_{4}$ & 33 & chair & equatorial & {$[25]$} \\
\hline (B) & -169 (anti) & ${ }^{3} \mathrm{~T}_{2}$ & 15 & chair & equatorial & \\
\hline cUMPE ${ }_{3} \mathrm{NH}$ (A) & -103 (anti) & ${ }_{4} \mathrm{~T}^{3}$ & 42 & chair & equatorial & [23] \\
\hline \begin{tabular}{|c|} 
\\
(B)
\end{tabular} & -122 (anti) & ${ }_{4} \mathrm{~T}^{3}$ & 48 & chair & equatorial. & \\
\hline $2^{\prime}$-acetyl-cUMP & $71($ syn $)$ & ${ }_{4} \mathrm{~T}^{3}$ & 49 & chair & equatorial & [33]. \\
\hline cIMP & -162 (anti) & ${ }^{3} \mathrm{~T}_{4}$ & 28 & chair & equatorial & [22] \\
\hline CCMP & -168 (anti) & ${ }^{3} \mathrm{~T}_{2}$ & & chair & equatorial & see [25] \\
\hline cTMPphenyl & $-98(a n t i)$ & ${ }_{4}^{3} \mathrm{~T}$ & & half chair & & [24] \\
\hline
\end{tabular}

\footnotetext{
* The torsion angle $\chi\left[\mathrm{O}^{\prime}-\mathrm{Cl}^{\prime}-\mathrm{N} 9-\mathrm{C} 4\right]$ may have been convented from the original paper if it was given as $\left[\mathrm{O}^{\prime}-\mathrm{Cl}^{\prime}-\mathrm{N}^{2}-\mathrm{C}^{-}\right]$.
}

** Listed in [25] as syn, but if the value is correct, it should be high syn which is actually anti. 

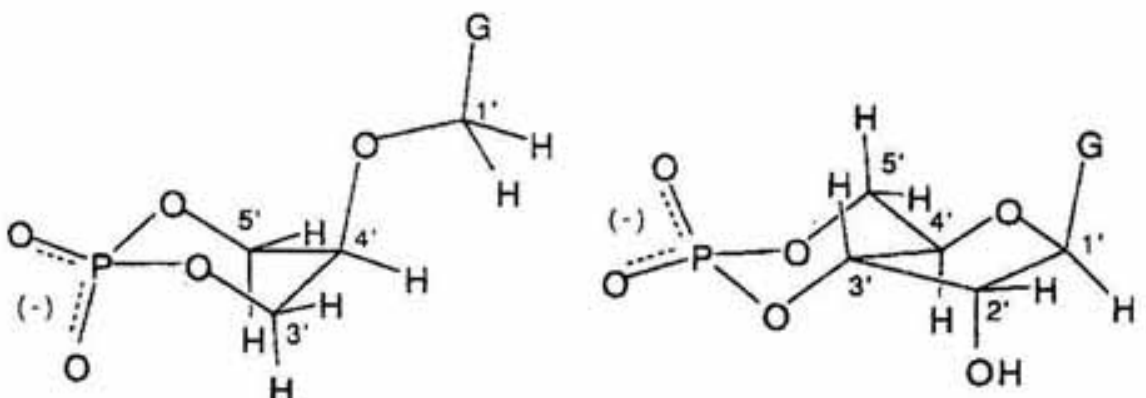

Fig. 5. Comparison of conformations of the cyclic phosphate rings of DHPG-cMP (left) and cGMP (right).

lated by intracellular levels of cAMP and cGMP $[1,15]$, a comparison of their structures is of interest. Another cyclic nucleotide of interest is cIMP, which was shown to be only slightly less potent than CAMP in stimulating CAMP-sensitive protein kinase in various tissues [20].

Some key structural features of several 3, $5^{\prime}$ cyclic mononucleotides are summarized in Table 4 . It shows that the fused cyclic phosphate and sugar rings have essentially the same conformations, while the relative orientations of the base and the sugar rings, as indicated by the glycosidic torsion angle $\chi$. vary a great deal. However, only syn conformations have been observed when the base is guanine, and that of the acyclic analogue DHPG-cMP is close to that with a $\chi$ value in the high syn region. This is supported by the energy calculations on $3^{\prime}, 5^{\prime}$-cyclic nucleotides [21] which show that CGMP prefers syn conformation while cAMP has a conformational preference for anti over syn in the ratio $7: 3$. The pyrimidine bases $U, T$, and $C$ all have strong preferences for anti conformation, and cIMP $\left(\chi=-162^{\circ}\right)$ [22], cUMP $\left(\chi=-103^{\circ}\right.$ and $\left.-122^{\circ}\right)$ [23], $\operatorname{cTMP}\left(\chi=-98^{\circ}\right)$ [24] and $\operatorname{cCMP}\left(\chi=-168^{\circ}\right)$ [25] all occur in the anti conformation.

Apart from CTMP, the cyclophosphate rings are all in a chair conformation that is flattened in the phosphate end and more puckered around the $\mathrm{C}^{\prime}-\mathrm{C} 4^{\prime}$ bond due to the fusion with the pentose ring. This distortion of the ring is not observed in the nucleotide analogue DHPG-cMP where there is no such fusion. The latter compound is also the only one with the $\mathrm{O}^{\prime}$ ' oxygen in the axial position relative to the cyclophosphate ring. The half chair that is observed in thymidine phenyl cyclic $3^{\prime}, 5^{\prime}$-monophosphate [24] is the intermediate conformation between a chair and the higher energy twist conformation.
Most of the pentose rings occur in the ${ }_{4} \mathrm{~T}^{3}$ conformation [C4' exo, C3' endo with more puckering at $\mathrm{C}^{\prime} \mathrm{l}$, but the similar conformations ${ }_{4}^{3} \mathrm{~T}$ [C4' exo, $\mathrm{C}^{\prime}$ ' endo with equal puckering at $\mathrm{C}^{\prime}$ ' and $\left.\mathrm{C}^{\prime}\right],{ }^{3} \mathrm{~T}_{4}\left[\mathrm{C}^{\prime}\right.$ ' exo, $\mathrm{C}^{\prime}$ 'endo with less puckering at $\left.\mathrm{C}^{\prime}\right]$ and ${ }^{3} \mathrm{E}\left[\mathrm{C}^{\prime}\right.$ ' endo with no puckering at $\mathrm{C}^{\prime} \mathrm{]}$ also occur. The pseudorotation phase angles $(\mathrm{P})$ lie in a wider range $\left(15^{\circ}-51^{\circ}\right)$ than earlier thought, and includealso the ${ }^{3} \mathrm{~T}_{2}$ conformation at the low end of this scale. The value for DHPG-cMP is outside this range with the sugar moiety being approximately a $\mathrm{C}^{\prime}$ endo envelope $\left({ }^{4} \mathrm{E}\right)$.

\section{Concluding remarks for DHPG-cMP}

The differences in the solid-state conformations of the sugar moieties between DHPGCMP and cGMP, and how they are linked to the cyclic phosphate rings result in differing relative orientations of the planes of the cyclic phosphate rings and aglycon (Fig. 6). In view of this it is remarkable that the distance between the aglycon and the cyclic phosphate ring in DHPG-cMP of 5.893(2) $\AA$ (the N9-P distance) is only $0.05 \AA$ greater than in cGMP $(5.846(2) \AA)$. This, together with the flexibility of the acyclic chain in DHPG-cMP, indicates possible reasonable overlap in the two structures despite the differences in conformations of the two compounds. The mechanism of antiviral activity of DHPG-cMP, which is different from that of the acyclonucleosides, may thus be linked to the fact that it is a close structural analogue to the second messenger cGMP.

\section{COMMON FEATURES}

\section{Base}

The guanine residues are usually fairly flat, which is the case for both $2 \mathrm{HM}-\mathrm{HBG}$ and 


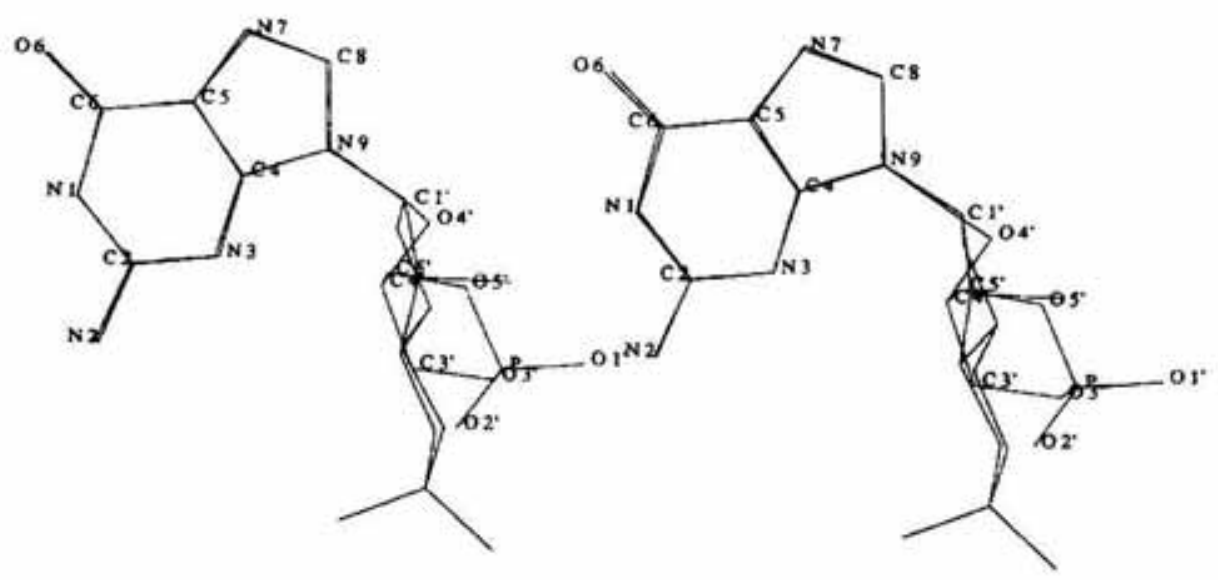

Fig. 6. Stereoscopic view of the superposition of the solid-state structures of DHPG-cMP and CGMP. Atoms in the DHPG-cMP molecule are numbered.

DHPG-cMP. Most of the exocyclic atoms, viz. $\mathrm{N} 2, \mathrm{O} 6$, and $\mathrm{Cl}^{\prime}$ are displaced from this plane by a small amount, but in both compounds the maximum deviation is no more than about $-0.08 \hat{A}$ (for $\mathrm{C1}^{\prime}$ and $\mathrm{O6}$, respectively) which is much less than in cGMP where it is as large as $0.184 \AA$ (for $\mathrm{C}^{\prime}$ ').

\section{Hydrogen bonding and packing}

Many of these compounds crystallize with water molecules, which play an important part in the hydrogen bonding scheme. This is the case for both 2HM-HBG and DHPG-cMP, as well as for ACV and CGMP sodium tetrahydrate. The molecules usually pack in such a way that the hydrophilic water regions are being alternated with hydrophobic ones, consisting of the guanine heterocycles, often forming $\pi-\pi$ stacks, such as in DHPG-cMP where the distances between atoms in the overlapping bases range from $3.157 \AA$ (C6"'C6) to $3.367 \AA$ (N3'" O6). This type of packing is a common feature in nucleoside and nucleotide crystal structures [26]. In 2HM-HBG where the guanine heterocycles do not form $\pi-\pi$ stacks, the hydrophobic heterocyclic regions still alternate with the hydrophilic regions.

\section{CONCLUSION}

It is clearly of interest to determine the role of the structure and conformation of a given analogue relative to those of the natural substrate. The comparison here of DHPG-cMP with its parent second messenger cGMP, previous comparisons of the crystal structures of acyclonu- cleosides such as ACV [11], DHPG and the analogous DHP-Ade [10] with their corresponding nucleosides, together with the solid state structures of HBG [8], 2HM-HBG, penciclovir and famciclovir [9] the $2^{\prime}, 3^{\prime}$-dihydroxypropyl derivatives of adenine [27] as well as 1-(2', 3'-O-isopropylidene-2', $3^{\prime}$-dihydroxypropyl)uracil [28] and 9-( 2 '-phosphonomethoxyethyl)adenine (PMEA) [12] lead to some general conclusions.

A characteristic feature of the above mentioned compounds is that not only is there "conformational flexibility" in solution of the acyclic chain, but also the co-existence of two (2HM-HBG, DHP-Ade, famciclovir), and even three (ACV) different conformers in the solid state. Sometimes two of the conformers have essentially the same conformation, but with some variation in dihedral angles, such as the molecules A and B of ACV and famciclovir. In addition to a form with the acyclic chain fully extended, there is often also a partially folded form, generally folded about the $\mathrm{C}^{\prime}-\mathrm{C}^{\prime}$ (or $\mathrm{C}^{\prime}-\mathrm{O}^{\prime}$ ) bond, which mimics the pentose ring of the natural nucleoside. In the case of $2 \mathrm{HM}-\mathrm{HBG}$ the partially folded chain is stabilized by an intra-molecular hydrogen bond.

In spite of the conformational flexibility of the acyclic chain, the glycosidic torsion angles for these antiviral agents, both the acyclonucleoside and the acyclonucleotide DHPG-cMP, are all in the syn or high syn conformation within a relatively narrow range, viz. from $69^{\circ}$ to $94^{\circ}$, with an average of $83(3)^{\circ}$ for 11 molecules (Tables 1 and $3 a$ ) when the aglycon is guanine, and from $92^{\circ}$ to $108^{\circ}$ with an average of $103(3)^{\circ}$ for 
4 molecules (Table 2) when the aglycon is adenine.

Hence, these experimental results support the suggestion based on theoretical calculations for ribavirin [29] that a glycosidic torsion angle within these ranges is essential to the antiviral activity. The flexibility of the acyclic chain, and its ability to adopt a number of conformations, including folded ones that mimic the pentose ring of the natural nucleoside or nucleotide, may also be essential for the ability of these compounds to act as substrates for nucleoside kinases, phosphodiesterases, nucleases, or protein kinases.

The work reported here was carried out in collaboration with Professor David Shugar and Dr Ryszard Stolarski - my sincere thanks go to both of them.

\section{REFERENCES}

1. Shugar, D. (1992) Phosphorylating enzymes involved in activation of chemotherapeutic nucleosides and nucleotides, in Molecular Aspects of Chemotherapy. Proceedings of the Third International Symposium, Gdarisk, Poland (Shugar, D., Rode, W. \& Borowski, E., eds.) pp. 239-271, Springer Verlag, Berlin, Polish Scientific Publishers PWN, Warsaw.

2. Birnbaum, K.B., Stolarski, R. \& Shugar, D. (1994) Structure and conformation of the cyclic phosphate of ganciclovir, a broad-spectrum antiviral agent. Biochim. Biophys. Acta 1200, 55-63.

3. Birnbaum, K.B., Stolarski, R. \& Shugar, D. (1995) Solid state and solution structure and conformation of the antiviral acyclonucleoside 9-[4-hydroxy-2-(hydroxymethyl)-butyl]guanine. Nucleosides \& Nucleotides 14, 1359-1377.

4. Larsson, A., Stenberg, K., Ericson, A.-C., Haglund, U., Yisak, W.-A., Johansson, N.G., Oberg, B. \& Datema, R. (1986) Mode of action, toxicity, pharmacokinetics, and efficacy of some new antiherpesvirus guanosine analogs related to buciclovir. Antimicrob. Agents Chemother. 30, 598-605.

5. Littler, E., Stuart, A.D. \& Chee, M.S. (1992) Human cytomegalovirus UL97 open reading frameencodes a protein that phosphorylates the antiviral nucleoside analogue ganciclovir. Nature (London) 358, 160-162.

6. Sullivan, V., Talarico, C.L., Stanat, S.C., Davis, M., Coen, D.M. \& Biron, K.K. (1992) A protein kinase homologue controls phosphorylation of ganciclovir in human cytomegalovirus-infected cells. Nature (London) 358, 162-164.

7. IUPAC -IUB Joint Commission on Biochemical Nomenclature (1983) Abbreviations and symbols for the description of conformation of polynucleotide chains. Eur. J. Biochem. 131, 9-15.

8. Birnbaum, G.I., Johansson, G. \& Shugar, D. (1987) Conformations of acyclonucleosides: crystal structure of 9-(4-hydroxybutyl)guanine, an analogue of acyclovir. Nucleosides \& Nucleotides 6, 775-783.

9. Harnden, M.R., Jarvest, R.L., Slawin, A.M.Z. \& Williams, D.J. (1990) Crystal and molecular structure of the antiviral acyclonucleoside 9-[4-hydroxy-3-(hydroxymethyl)butyl]guanine (BRL 39123, Penciclovir) and its prodrug 9-[4-acetoxy-3-(acetoxymethyl)butyl]-2-aminopurine (BRL 42810, Famciclovir). Nucleosides \& Nucleotides 9, 499-513.

10. Granzin, J., Saenger, W., Stolarski, R. \& Shugar, D. (1990) Solid state and solution structures of an adenine analogue of the antiviral acyclonucleoside 9-(1,3-dihydroxy-2-propoxymethyl)guanine. Z. Naturforsch. 45c, 915-921.

11. Birnbaum, G.I., Cygler, M. \& Shugar, D. (1984) Conformational features of acyclonucleosides: structure of acyclovir, an antiherpes agent. Can . J. Chem. 62, 2646-2652.

12. Schwalbe, C.H., Thomson, W. \& Freeman, S. (1991) Structural studies on bio-active molecules. Part 17. Crystal structure of 9-(2' -phosphonomethoxyethyl)adenine (PMEA). J. Chem. Soc. Perkin Trans. 1, 1348-1349.

13. Tolman, R.L., Field, A.K., Karkas, J.D., Wagner, A.F., Germershausen, J., Crumpacker, C. \& Scolnic, E.M. (1985) 2'-nor-cGMP: a seco-cyclic nucleotide with powerful anti-DNA viral activity. Biochem. Biophys. Res. Commun. 128, 1329-1335.

14. Oliver, S., Bubley, G. \& Crumpacker, C. (1985) Inhibition of HSV-transformed murine cells by nucleoside analogues, 2 '-NDG and 2'-norCGMP: mechanism of inhibition and reversal by exogenous nucleosides. Virology 145, 84-95.

15. Cieśla, J.M., Stolarski, R. \& Shugar, D. (1993) Cyclic phosphates of some antiviral acyclonucleosides: relationship between conformation and substrate/inhibitor properties in some enzyme systems. Acta Biochim. Polon. 40, 251-260, and references therein.

16. Yang, Z.H., Lucia, H.L., Tolman, R.L., Colonno, R.J. \& Hsiung, G.D. (1989) Effect of 2 -nor-cyclic GMP against guinea pig cytomegalovirus 
infection. Antimicrob. Agents Chemother. 33, 1563-1568.

17. Chwang, A.K. \& Sundaralingam, M. (1974) The crystal and molecular structure of guanosine 3',5'-cyclic monophosphate (cyclic GMP) sodium tetrahydrate. Acta Cryst. B30, 1233-1240.

18. Druyan, M.E. \& Sparagana, M. (1976) The molecular structure of the free acid of guanosine 3',5'-cyclic monophosphate (cyclic GMP). J. Cyclic Nucleotide Res. 2, 373-377.

19. Goldberg, N.D., Haddox, M.K., Dunham, E., Lopez, C. \& Hadden, J.W. (1974) in Control of Proliferation in Animal Cells; vol. 1, pp. 609-625, Cold Spring Harbor Symposium, Cold Spring Harbor Laboratory, Cold Spring Harbor, New York.

20. Corbin, J.D. \& Krebs, E.G. (1969) A cyclic AMP-stimulated protein kinase in adipose tissue, Biochem. Biophys. Res. Commun. 36. 328-336.

21. Yathindra, N. \& Sundaralingam, M. (1974) Conformation of cyclic 3',5'-nucleotides. Effect of the base on the syn-anti conformer distribution. Biochem. Biophys. Res. Commun. 56, 119-126.

22. Sundaralingam, M., Haromy, T.P. \& Prusiner, P. (1982) The structure of the zwitterion inosine cyclic 3',5'-monophosphate (cIMP) monohydrate. Analysis of torsional flexibility in the furano-phosphate moiety. Acta Cryst. B38, 1536-1540.

23. Coulter, C.L (1969) The crystal and molecular structure of the triethylammonium salt of cvclic uridine- 3 ', 5 '-phosphate. Acta Cryst. B25, 2055-2065; (1970) 26, 441.

24. Neison, K.A., Bentrude, W.G., Setzer, W.N. \& Hutchinson, J.P. (1987) The question of chairtwist equilibria for the phosphate rings of nucleoside cyclic $3^{\prime}, 5^{\prime}$-monophosphates. ${ }^{1} \mathrm{H}$ NMR and X-ray crystallographic study of the diastereomers of thymidine phenyl cyclic 3',5'-monophosphate. J. Am. Chem. Soc. 109, 4058-4064.

25. Varughese, K.I., Lu, C.T. \& Kartha, G. (1982) The crystal and molecular structure of cyclic adenosine $3^{\prime}, 5^{\prime}$-monophosphate sodium salt, monoclinic form. J. Am. Chem. Soc. 104, 3398-3401, and references therein.

26. Swaminathan, V. \& Sundaralingam, M. (1979) The crystal structures of metal complexes of nucleic acids and their constituents. CRC Crit. Rev. Biochem. 6, 245-336.
27. King, G.S.D. \& Sengier, L. (1981) Crystal structure of two forms of 9-(2,3-dihydroxypropyl)adenine. J. Chem. Res. (M), 1501-1538.

28. Kaiser, P.M. \& Lindner, H.J. (1982) Crystal structure of 2,3'-O-isopropylidene-(S)-1-(2,3dihydroxypropyl)uracil; in Nucleosides, Nucleotides and their Biological Applications (Alderweireld, F.C. \& Esmans, E.L., eds.) pp. 293-302, University of Antwerp.

29. Miles, D.L., Miles, D.W. \& Eyring, H. (1981) Implications of a circular dichroism and theoretical investigation of ribavirin-related derivatives in drug design. Ann. N.Y. Acad. Sci. $367,518-530$.

30. Watenpaugh, K., Dow, J., Jensen, L.H. \& Furberg, S. (1968) Crystal and molecular structure of $3^{\prime}, \overline{5}^{\prime}$-cyclic phosphate. Science 159, 206-207.

31. Sundaralingam, M. \& Abola, J. (1972) Stereochemistry of nucleic acids and their constituents. XXVII. The crystal structure of $5^{\prime}$ -methyleneadenosine $3^{\prime}, 5^{\prime}$-cyclic monophosphonate monohydrate, a biologically active analog of the secondary hormonal messenger cyclic adenosine 3,5'-cyclic monophosphate. Conformational "rigidity" in furanose ring cyclic nucleotides. J. Am. Chem. Soc. 94, 5070-5076.

32. Sheldrick, W.S. \& Rieke, E. (1978) 8-[(2-Aminoethyl)aminoladenosine cyclic $3^{\prime}, 5^{\prime}$-monophosphate tetrahydrate. Acta Cryst. B34, 2324-2327.

33. Depmeier, W. \& Engels, J. (1977) The crystal and molecular structure of $2^{\prime}$-acetyluridine- $3^{\prime}, 5^{\prime}$ cyclophosphate benzyl triester, a pyrimidine nucleotide with syn conformation. Acta Cryst. B33, 2436-2440. 